\title{
Plain Talk About Health: Linguistic Aspects of Mediation between Amish and Mennonites and Health Care Professionals
}

\author{
Mark L. Louden \\ Alfred L. Shoemaker, J. William Frey, and Don Yoder Professor of Germanic Linguistics \\ University of Wisconsin-Madison \\ mllouden@wisc.edu
}

\begin{abstract}
As the population of Amish and Old Order Mennonites grows exponentially, so are the contacts between Plain people and medical professionals increasing. All Plain adults are bilingual; however, the fact that the primary everyday language for most is Pennsylvania Dutch is important for understanding how they navigate the health care system. In this article I give an overview of language-related questions involved in communication between Plain people and health care providers with a focus on three areas: translation, interpretation, and patterns of language use. Much of the information I present in this article is drawn from my experience as an interpreter and cultural mediator for Plain people in a number of different public spheres, mainly health care.
\end{abstract}

Submitted June 12, 2020; accepted June 22, 2020; published September 18, 2020

https://doi.org/10.18061/jpac.v1i1.7803

Keywords: Pennsylvania Dutch language; health care; bilingualism; translation; interpretation; language contact; language use; Amish, Old Order Mennonites

\section{Introduction}

For several years now, the Young Center for Anabaptist and Pietist Studies at Elizabethtown College has sponsored international conferences devoted to the field of Amish studies. The focus of the conference held in June 2019 was Health and Well-Being in Amish Society, which recognized the increasing importance of questions related to the health of Amish and other Plain groups and their interactions with the health care system. The conference brought together researchers and professionals involved in the delivery of health care to Plain people as well community members themselves to explore biomedical, spiritual, cultural, and practical (e.g., financial) topics. The scope of the presentations at the Young Center conference underscored the fundamental diversity of the scholarly field of Amish studies and its relevance to the broader public.

Much of the large and growing body of scholarly literature on Amish and Old Order Mennonite health and well-being deals, understandably, with complex biomedical topics (e.g., genetic disorders) as well as practical information for nurses, midwives, physicians, and others who care for Plain patients. Other researchers have focused on cultural aspects of Plain health (Wenger 1995; Huntington 2003; Kraybill, Johnson-Weiner, and Nolt 2013, 335-51; King 2014). Language matters are discussed only occasionally in works such as these; hence, the motivation for this article, which is based on a presentation I delivered at the 2019 Young Center conference that 
draws on my scholarly background in Pennsylvania Dutch linguistics and practical experience as an interpreter and cultural mediator for Plain people. Although not born into an Old Order family, I am a Mennonite and became fluent in Pennsylvania Dutch early in life. The language, faith, and culture of its speakers are the focus of my professional career, an important component of which is public outreach. For several years now, I have been asked to assist in situations in which Plain people interact with outsiders, most frequently in the area of health care.

In what follows I present an overview of the major questions related to language in contexts in which Amish and traditional Mennonites interact with the health care system. I begin by providing background information on the sociolinguistic situation in Plain communities, in which bilingualism is the norm. I then discuss aspects related to Pennsylvania Dutch-English translation and interpretation, before concluding with some observations about how Plain people use language generally and how their speech patterns can affect the ways they are perceived by health care providers.

\section{Plain Bilingualism}

A discussion of any aspect of language use among Plain people will necessarily involve the question of their bilingualism. As a rule, the first language acquired by children born into Amish or Old Order Mennonite (hereafter, "Mennonite") families is a German-related language, most commonly Pennsylvania Dutch (Louden 2016). A small minority of Amish known as Swiss Amish or Shwitzer speak one of two languages, Amish Swiss German or Amish Alsatian German (Louden 2019, 1148-49). Swiss Amish are descended from nineteenth-century immigrants mostly from the Alsace region who first settled in Ontario and Ohio and then migrated westward, mainly to Indiana and Illinois. The largest concentrations of Swiss Amish are in Adams, Allen, and Jay counties in Indiana (Nolt and Myers 2007, 58-70). In what follows I will focus on Pennsylvania Dutchspeaking Plain people, though the overall sociolinguistic features of Swiss Amish bilingualism are largely the same.

Preschool-age Plain children typically remain monolingual in Pennsylvania Dutch until they enter school, which for most are Old Order-run schools in which the medium of instruction is English. Smaller numbers of children attend public schools or are homeschooled, but there again, the material is delivered in English. German is taught as a subject in Plain schools, often on Friday afternoons. The goal of German instruction is to promote basic literacy in the form of the language that is used in worship - that is, the German of Martin Luther's translation of the Bible and hymn and prayer books (Johnson-Weiner 2007, 183-87). Amish High German (PD Hochdeitsch), as this written language is commonly referred to, is somewhat archaic when compared to the standard German used in contemporary Central Europe, not unlike the difference between the English of the King James Bible and the modern language (Louden 2016, 331-41).

Immersed in an all-English educational setting, most Plain children become bilingual quite rapidly, such that by the time they leave school after the eighth grade, their oral proficiency in Pennsylvania Dutch and English is more or less equivalent. As is the norm in other bilingual communities, certain topics will be more easily discussed in one language than the other. For 
example, Amish and Mennonites usually find it easier to talk about community-internal subject matter, especially matters related to their faith, in Pennsylvania Dutch, whereas things that they have learned through interactions with outsiders or in school, such as arithmetic, lend themselves to the use of English.

With regard to Plain literacy, English is the dominant language of writing and most reading, apart from textual material used for worship and personal devotion. Although Pennsylvania Dutch has been put to paper, most notably in a translation of the Bible produced by native speakers of Amish background (Di Heilich Shrift 2013), rarely will Plain people write anything in their mother tongue beyond an occasional word in personal correspondence (Louden 2016, 341-52). This is anomalous for English-monolinguals in North America, who, with some stylistic variation, read, write, and speak the same language. The Plain sociolinguistic situation is not unlike that of postcolonial multilingual societies in which indigenous languages are spoken alongside a standardized language, such as English, French, or Spanish, which is the dominant or sole medium of literacy. In Europe, there are similar cases, notably German-speaking Switzerland. Spoken Swiss German dialects are not mutually intelligible with standard German, which is what Swiss Germans speak and write in schools and in many workplaces.

Before proceeding to a discussion of Pennsylvania Dutch-English translation and interpretation, a few remarks about linguistic features of Pennsylvania Dutch and specifically the influence of English on it are in order. Pennsylvania Dutch (or Pennsylvania German, the name preferred by many scholars) developed in the second half of the eighteenth century among the descendants of migrants from southwestern Germany, Alsace, and Switzerland, who spoke the dialects of the regions from which they hailed. The great majority of immigrants came from the Palatinate region (Pfalz), which is located in southwestern Germany, near the city of Mannheim; thus, Pennsylvania Dutch most closely resembles Palatine German dialects in its core areas of grammar (its systems of sounds, word formation, and sentence structure) as well as its vocabulary (Louden 2016, 1-62).

All languages, especially those used in bilingual communities or in societies with a legacy of immigration, show the effects of contact from other languages, notably in the form of borrowed words. English, for example, a historically Germanic language, and especially American English, derives about three-quarters of its vocabulary from non-Germanic sources, notably French or Latin (e.g., language, medicine, music) and Greek (e.g., ethnic, telephone, zoo), but also other languages, like Spanish (taco), Italian (balcony), Russian (mammoth), Yiddish (chutzpah), Japanese (tsunami), and even Pennsylvania Dutch (dunk). Pennsylvania Dutch, as a language whose speakers have always been a minority in an English-speaking society, has naturally borrowed many words from the majority language, though considerably fewer than many people, including native speakers, assume.

Approximately 10-15 percent of Pennsylvania Dutch vocabulary is taken directly from English (loanwords), usually words that refer to objects and concepts that were not familiar to the eighteenth-century founding population. The influence of English on Pennsylvania Dutch extends 
further, in a less obvious way, on the level of meaning (semantics). Once, when asked why Pennsylvania Dutch is so different from the German spoken in Europe, a native speaker remarked, "Fer Deitsch schwetze, musscht du Englisch denke" (Louden 2020; To speak Pennsylvania Dutch, you need to think in English). There is truth in that observation, as we can see in the following examples from the semantic area most relevant to this article, namely health and well-being.

The words for body parts and basic bodily functions are typically not borrowed from one language into another. In the Pennsylvania Dutch context, eighteenth-century immigrants did not encounter heads, hands, and feet for the first time after their arrival in North America, nor did they learn to breathe or burp here. Not surprisingly, then, when speaking about basic anatomy and physiology in Pennsylvania Dutch, mostly inherited (native) vocabulary is used, as with en verbroche Bee (a broken leg). But as medical science has progressed since the colonial era, the English words used in this semantic area are naturally borrowed into Pennsylvania Dutch, for example, hospital. In the eighteenth century and later, injured or ill Americans were treated at home. Hospitals in the modern sense did not exist until later, so it makes sense that when they were established in the United States, Pennsylvania Dutch speakers simply called them Hospitals. English-derived loanwords for medical terminology are, not surprisingly, very common in Pennsylvania Dutch. It is notable that in virtually every case, English words like hospital are themselves borrowed, in this case from Latin/French. Other examples of Latinate English words are digestion, monitor, treat. Greek is also the source of much medical terminology in English (e.g., antibiotic, cardiology, thermometer), including by way of French (e.g., clinic).

Aside from loanwords, the semantic influence of English on Pennsylvania Dutch can be seen in three types of vocabulary: loanblends, loanshifts, and loan translations. Loanblends are compound words that combine native and borrowed elements in translations from one language into another. Examples of these abound in Pennsylvania Dutch, including Emergency-Schtubb and Operating-Schtubb (Schtubb 'room'). Loanshifts refer to native words that have had their original meaning adapted to match a similar word in the influencing language, such as the verb doktere 'to treat medically, doctor'. Finally, loan translations are compound words and expressions that are translated verbatim from one language to another, as in the Pennsylvania Dutch word for 'medicine', Dokter-Schtofft, which is modeled on the nineteenth-century colloquial American English expression doctor stuff.

\section{Translation}

The intensity of Plain bilingualism and the extent to which English affects the vocabulary of Pennsylvania Dutch raise the question of whether translation (which refers to the production of written texts) and interpretation (oral linguistic mediation) between the two languages is necessary. Strictly speaking, for school-age children and adults they are not; however, there are definite benefits for making language assistance available to Amish and Mennonites when desired, especially in the area of health care. 
Looking first at translation, in recent years there has been an increase in the demand for documents from hospitals, insurers, and government agencies to be rendered from English into Pennsylvania Dutch. With regard to health care in the United States, a major motivation on the part of these organizations derives from concerns about improving "health literacy," which the Health Resources and Services Administration, part of the US Department of Health and Human Services, defines as follows (https:/www.hrsa.gov/about/organization/bureaus/ohe/health-literacy /index.html):

Health literacy is the degree to which individuals have the capacity to obtain, process, and understand basic health information needed to make appropriate health decisions.

Lower health literacy is more prevalent among:

- Older adults

- Minority populations

- Those who have low socioeconomic status

- Medically underserved people

Plain people, as members of a distinctive minority population, most with modest incomes and limited formal educational levels, whom some consider medically underserved, are thus on the radar of health care providers located in regions with relatively large numbers of Amish and Mennonites. The fact that they also speak a language other than English, even if they are fluent and completely literate in English, heightens the concern that this may pose an additional challenge to their health literacy. In the American public mind, the ability to be more or less equally proficient in multiple languages, at least on the oral level, as Plain people are, is hard to grasp. The assumption among many is that if someone in this country speaks a non-English language fluently, especially a member of a minority community of low socioeconomic status, that person likely does not speak English well or at all.

Effective translations of written material from English into Pennsylvania Dutch are guided by a truism about translation in general, namely that the process involves rendering the overall meaning of a text from one language into the other and not striving to match individual words between the languages. Some people who have attempted to translate from English into Pennsylvania Dutch have taken pains to avoid using any English loanwords, preferring instead to create novel words based on Pennsylvania Dutch roots. While loan translations like DokterSchtofft are a natural part of the lexical fabric of Pennsylvania Dutch, if they are not created by native speakers themselves and codified through community usage, speakers will either laugh them off or not understand them at all. Worse yet are collocations known as loan creations, which are often motivated by linguistic purism accompanied by linguistic chauvinism. The short-lived rendering of sauerkraut as liberty cabbage is one infamous example of a loan creation in American English. In Pennsylvania Dutch, a similar example is Schwetzkaschde, literally "talk box," which 
was originally intended to refer to a phonograph and is now on occasion used by non-native users of Pennsylvania Dutch to mean 'radio'; in actual Pennsylvania Dutch, only Radio is used.

Since English-derived words are a natural part of the Pennsylvania Dutch lexicon, they belong in texts translated into the language. However, a challenge is posed by English words that are unfamiliar to Plain people, especially those that are part of specialized or technical terminology. This is not only a hurdle for Plain people, but indeed for many English monolinguals as well and something that makes improving health literacy more difficult. In instances where an unfamiliar term is used, translators do best to either include the English original and then explain it or simply circumlocute. The problem posed by highly complicated language that is inaccessible to average speakers has been recognized by organizations like government agencies and health care providers and addressed by using so-called plain language (with a lower-case "p") (Stableford and Mettger 2007). As an example, below are two versions of a short text taken from the Manual of Administrative Policy produced by WellSpan Health, a health care system that serves many Plain people (with a capital "P") in southeastern Pennsylvania. The original text is followed by a translation into plain language.

Consistent with its charitable mission of "working as one to improve health through exceptional care for all, lifelong wellness and healthy communities," WellSpan Health provides financial assistance to eligible patients who are in need. The Financial Assistance Policy will be fair, efficient and accessible to all patients and will be consistently applied across all WellSpan Health entities. (https://www.wellspan.org/media/1920317/10853 _WellSpan-Health-MAP-118-219.pdf)

As part of its charitable mission, WellSpan Health is committed to providing exceptional care for all members of the communities it serves. We recognize some patients and families may need financial assistance to help with the cost of health care. WellSpan Health offers financial assistance through its Financial Assistance Policy to ensure access to high-quality care for all. (https://www.wellspan.org/media/1357713/5463b_FinancialAssist-PlainLang -Summary.pdf)

A good rendering of this text from WellSpan Health into Pennsylvania Dutch follows more closely the plain language version, as the verbatim English translation below it demonstrates.

Die Mission vun WellSpan Health is as sie Leit helfe welle. Fer sell duh, welle sie die bescht Care gewwe zu alli Leit as in die Communities wuhne as sie serv-e. Mir wisse as deel Leit Hilf brauche zeele fer bezaahle fer die Care. WellSpan Health dutt so Leit helfe darrich ihre Financial Assistance Policy so as alliebber die bescht Care griege kann. 
The mission of WellSpan Health is that they want to help people. In order to do that, they want to give the best care to all people who live in the communities they serve. We know that some people need help paying for care. WellSpan Health helps such people through their Financial Assistance Policy so that everyone can get the best care.

The Pennsylvania Dutch translation notably includes a number of loanwords, such as Mission, Care, Communities, and serv-e (pronounced "serve-uh") that have no equivalent in Pennsylvania Dutch but are still familiar to Plain people. Terms such as "WellSpan Health" and "Financial Assistance Policy," as proper names, are automatically rendered verbatim in Pennsylvania Dutch. Since Plain people have little experience reading texts in their first language, it is quite likely that they may be better served by materials rendered in plain English than translated into Pennsylvania Dutch. However, by providing translations of important documents into multiple languages, organizations and agencies signal to the people they serve that they respect the communities in which these languages are used, which can be a powerful expression of support for cultural diversity. Especially for the speakers of Pennsylvania Dutch, which has a legacy of being stigmatized as "not a real language" or a "bastardized" mixture of German and English, such signs of respect are meaningful.

\section{Interpretation}

Pennsylvania Dutch-English interpretation, which involves oral communication in real time, is routine for preschool-age Plain children and is normally conducted by parents; however, under special circumstances, such as forensic interviews, parents and other family members may not be present. But even many Amish and Mennonite adults welcome the opportunity to have interpreters present during serious medical conversations, in the same way that many patients and family members appreciate having multiple "sets of ears" in those settings, both to ensure that they have understood everything a provider has shared and for emotional support.

For Plain people, the use of Pennsylvania Dutch connotes trust, honesty, and a familiarity and respect for their culture, which is grounded in a Christian faith that infuses their daily living. In my own experience as a medical and legal interpreter, on multiple occasions Plain people have said things like, "Es schpiert yuscht gut fer ebber do hawwe as ich Deitsch schwetze kann demit" (It just feels good to have someone here that I can talk Dutch with). The positive associations attached to Pennsylvania Dutch by its speakers are not limited to Plain people. So-called Fancy Dutch or Church People, Pennsylvania Dutch speakers of mainly Lutheran and Reformed background whose ancestors comprised the majority of speakers into the twentieth century, have expressed similar views. One such person was Russel Wieder Gilbert (1905-1985), a native speaker of Pennsylvania Dutch and professor of German at Susquehanna University in Pennsylvania, who reflected on the use of his mother tongue in speeches at fersommlinge, public gatherings to celebrate Pennsylvania Dutch language (“dialect") and culture. 


\begin{abstract}
Almost automatically, the use of dialect creates a positive speaker-audience relationship. Dialect is superlatively closer to the soil than the literary language. The conversational and colloquial quality, difficult to translate, produces a cordiality and unanimity of feeling unprecedented in speech annals. The bond between speakers and listeners is perfect. Try to sell a Pennsylvania German something in English, and mistrust may forbid the sale. The companionship of the dialect will warm the cockles of his heart. Ideas glorifying Pennsylvania German accomplishments in his own Mundart [dialect], simple, unhewn, and unsophisticated, can engender uncommon enthusiasm for even the commonplace. (Gilbert $1956,5)$
\end{abstract}

Plain people often express similar metalinguistic views about the difference between Pennsylvania Dutch and English, more precisely, the circumstances under which the languages are used. Even though Amish and Mennonites speak and read and write English fluently, it still has an "outsider" quality to it, as the sole language of the larger, non-Plain society. This alienness is reinforced by what happens when people who grow up in Old Order families leave the fold: in most cases, the transition to using English only is rapid. While Plain people recognize that no language in inherently virtuous, the use of English is often connected with prideful behavior, the antithesis of humility (Demut in both Pennsylvania Dutch and German), a cardinal virtue toward which Amish and Mennonites strive (1001 Questions and Answers 1992, 78-81; Hostetler 1993, 21-22). Bishop Joseph O. Wenger (1868-1956), the namesake of the horse-and-buggy-driving Wenger (Groffdale Conference, Team) Mennonites, has been quoted as having this to say about the use of English: "S' is nix letz mit die englisch Schprooch. Es scheint awwer wann die deitsche Leit mol englisch warre welle, dann dutt der Hochmut sich eischtelle" (Hoover 2018, 59; There's nothing wrong with the English language. But it seems that when German people make an effort to become English, pride is getting a foothold).

The comfort offered by the use of Pennsylvania Dutch in medical contexts, especially critical situations, is aptly illustrated by the story of an Amish-born nurse, Crist Beiler, who works in the Emergency Department of Lancaster General Hospital (LGH) and serves as a medical interpreter. Two anecdotes from a 2018 online article about Beiler's work underscore the importance of medical interpretation generally, which involves more than merely conveying information from one person to another (Lines 2018).

Beiler's value as a medical interpreter goes beyond his skills as a translator. His innate cultural competence enables him to provide a higher level of comfort to Amish patientsespecially children. Beiler recalls recently helping a young boy from the Amish community whose injuries required him to be transferred to a pediatric hospital. While riding with three medical personnel, the boy remained quiet - that is, until Beiler started speaking to him in Pennsylvania Dutch. 
"From that moment on, he became animated and talked for the entire ride, telling me about his school and his family," Beiler said. "For a small child-especially one who is brought back to the trauma bay, with a group of strangers looming above - just knowing there is someone with you who understands your first language can be very reassuring."

That Pennsylvania Dutch-English interpretation is appropriate also for adults is demonstrated by the second anecdote about Crist Beiler (Lines 2018).

Beiler completed LEAP [Linguistic Employee Advancement Program] training in January and already helped intervene in a special case. A pediatric patient at LGH experienced a serious breathing issue. After pursuing several care approaches, the medical team started to investigate transferring the patient to a dedicated pediatric facility for more advanced care. The lead physician on the case asked the patient's family for approval to transfer the child, but the family refused. Then, Beiler asked if he could step in.

"The father spoke English, but he didn't fully understand the situation," Beiler said. "I spoke with him in Pennsylvania Dutch, and quickly realized that he did not want his son to be intubated, because he thought this was how his son would have to live the rest of his life. Within minutes he understood that intubation was a temporary but necessary step, and he agreed to the transfer."

\section{Language Use}

In this final section I discuss distinctive aspects of how Plain people express themselves in both Pennsylvania Dutch and English when speaking about health and related topics, in the context of more general patterns about how they conduct themselves verbally and nonverbally. Amish and Mennonites often use language in ways that set their speech apart from that of outsiders with whom they interact, including health care providers, which can on occasion lead to misunderstandings. In a manual written for Amish youth that provides answers to important questions about how to live out their faith, there is a section titled "Our Speech" (1001 Questions and Answers, 111-15). One question in this section is "What guidelines does the Bible give us by which to monitor our speech?" The unnamed editors of the book offer seven recommendations for how Christians should speak, each supported by passages from Scripture (p. 113).

1. To speak only the truth

2. To be simple and straightforward in our speech

3. To be "slow to speak"

4. To return good for evil

5. Sometimes it is better to be quiet

6. To be consistent in our speech

7. To be a good witness to non-Christians 
Each of these guidelines is consistent with the virtue of humility that is at the center of Old Order life but often at odds with the ways that other Americans conduct themselves in their actions and their speech, especially in public. An apt example of verbal humility among Plain people is their reluctance to make definite statements about the future, which is not uncommon in many traditional societies, including German-speaking Europe, but anomalous for many non-Plain outsiders. For example, Amish and traditional Mennonites avoid expressions such as "I'll see you next week," when speaking both Pennsylvania Dutch and English. Instead, they might say, "Wann nix letz geht, sehn ich dich naegscht Woch" (If nothing goes wrong, I'll see you next week). The underlying thought here is that it is bordering on the prideful if one were to assume that anything, aside from that which is divinely ordained, will definitely occur in the future.

The avoidance of speaking about the future with certainty partly explains the caution Plain people feel in discussions of pregnancy and childbirth. In Pennsylvania Dutch, there is a word for "pregnant," schwanger (identical in German), but the only time this word is ever used is when quoting from the Luther Bible. The preferred expression in Plain Pennsylvania Dutch is an ekschpeckte sei (to be expecting), which is both a euphemism and a borrowing from English. Even though pregnancy is a frequent phenomenon in Old Order communities, Plain people have inherited a reluctance to speak about the hoped-for outcome of pregnancy, a normal birth. To assume that all will go well for baby and mom would be tantamount to tempting God. The complete nonexistence of baby showers in Plain society is a cultural expression of the seriousness with which expectant mothers and their relatives conduct themselves, also verbally, during that time.

In the medical context, while many providers often are careful to speak of outcomes as probabilities rather than certainties, expressions like the following are not uncommon: "If that happens, the patient will die." A Plain person would feel more comfortable saying something like, "Wann sell haeppent, is der Patient aept fer schtarrewe" (If that happens, the patient is likely to die). This caution about the future, coupled with the confidence among Amish and Mennonites that God is in control, can lead medical professionals to think that Plain people are "fatalistic," which can be problematic when a child is a patient (Kraybill, Johnson-Weiner, and Nolt 2013, 335-36). On many occasions, health care providers form the mistaken impression that Plain parents care less about their children's health than they actually do. The tendency for Plain people to be "slow to speak," especially in an unfamiliar setting and in English, can reinforce this impression.

Other factors that suggest to medical professionals that Amish and Mennonites may be insufficiently concerned about their own health or that of family members has to do with their desire "to speak only the truth," what may be termed verbal integrity. Unlike English monolinguals, Plain people avoid using turns of phrase that on the surface are falsehoods, even if they are being used figuratively. For example, saying things like "I'm freezing" or "I'm starving" when one is especially cold or hungry is viewed as inappropriate unless one is actually freezing or dying of hunger. Likewise, Amish and Mennonites regularly avoid superlatives like "that's the best pie I ever ate." The trend toward verbal integrity means that when Plain patients are asked to rate any pain they may experience on a scale of 1 to 10, they would be inclined to stop at 6 or 7 
out of principle. In general, Amish and Mennonites prefer to be understated in their behavior and speech. I recall the Amish mother of a hospitalized child telling that child, "Du darfscht brutze, awwer du darfscht net greische" (You can cry, but you can't scream). If the medical staff tending to the child had understood what the mom had said, they might have felt she was uncaring about her child's suffering. From the mother's perspective, screaming about pain would do nothing to relieve it, so it was best to avoid what was to Plain thinking an overreaction.

Verbal integrity is thus a virtue that Plain people aim to embody in their speech, including when accessing health care, and they appreciate it when the providers of that care do likewise. Amish and Mennonite patients, like most people, are grateful when providers take the time to listen to patients and their families and explain diagnoses and treatment options in plain language and without rushing. Some providers have remarked that their Plain patients ask more questions than their non-Plain patients, which has in part to do with a general interest in health and well-being and is also connected with their preference for accessing care within the community, thereby avoiding doctors and hospitals as much as possible.

\section{Conclusion}

In 2016, an online magazine devoted to science and health featured an article titled "Six Ways to Make a Hospital Better for Amish Patients" (Talpos, 2016), which was based on the experiences of Pomerene Hospital in Holmes County, Ohio, the largest Amish settlement in the world. Practical suggestions included hiring a patient advocate who knows Plain culture and Pennsylvania Dutch, providing nonstarched head coverings for female patients, being respectful and supportive of the Amish-created B\&W/burdock protocol for the treatment of burns, and not assuming that Amish women have no say in the care they receive. But the first suggestion the article offered had to do with language and was titled "Bisli Deitsh gayt en langa vayk" (A little Dutch goes a long way):

Pennsylvania Dutch is an outgrowth of German, which was spoken by many of the central Europeans who migrated to Pennsylvania in the 1700s. Today, most Amish speak Pennsylvania Dutch among themselves and English with everyone else (hence why they refer to non-Plain people as "English").

Last summer, Pomerene Hospital invited an Amish schoolteacher to lead a ten-week language course, open to all staff. A little Dutch can go a long way: once, an elderly man who had had a stroke wasn't responding to his nurse's prompts. When another nurse tried Pennsylvania Dutch — the language of his earliest years - he responded.

There is a steep learning curve for health care providers who seek to understand better the faith and culture of their Amish and Mennonite patients, which includes becoming familiar with their language situation. As the experiences of facilities such as Pomerene Hospital show, even a little Dutch — and some knowledge about how that language is used — does indeed go a long way toward delivering care in a culturally sensitive and ultimately more effective way. 


\section{References}

1001 Questions and Answers on the Christian Life. 1992. Aylmer, ON: Pathway Publishers. Di Heilich Shrift. 2013. Wycliffe Bible Translators.

Gilbert, Russell W. 1956. "Pennsylvania German Versammling Speeches." Pennsylvania Speech Annual 13: 3-20.

Hoover, Amos B. 2018. German Language, Cradle of Our Heritage: Struggles with Language Change among Mennonites. Ephrata, PA: Muddy Creek Farm Library.

Hostetler, John A. 1993. Amish Society. 4th ed. Baltimore: Johns Hopkins University Press.

Huntington, Gertrude Enders. 2003. "Health Care." In The Amish and the State, 2nd ed., edited by Donald B. Kraybill, 163-89. Baltimore: Johns Hopkins University Press.

Johnson-Weiner, Karen M. 2007. Train Up a Child: Old Order Amish and Mennonite Schools. Baltimore: Johns Hopkins University Press.

King, Martha Elizabeth. 2014. "Cultural Contexts of Health and Illness among the Lancaster Amish.” PhD diss., University of North Carolina at Chapel Hill. https://doi.org/10.17615/zhn2-zw56

Kraybill, Donald B., Karen M. Johnson-Weiner, and Steven M. Nolt. 2013. The Amish. Baltimore: Johns Hopkins University Press.

Lines, John. 2018. "Speaking the Language of Medicine." Penn Medicine News, April 12. https://www.pennmedicine.org/news/news-blog/2018/april/speaking-the-language-ofmedicine.

Louden, Mark L. 2016. Pennsylvania Dutch: The Story of an American Language. Baltimore: Johns Hopkins University Press.

Louden, Mark L. 2019. "Deutsch als Minderheitensprache in Nordamerika." In Sprache und Raum: Ein Internationales Handbuch der Sprachvariation, Vol. 4, Deutsch, edited by Joachim Herrgen and Jürgen Erich Schmidt, 1135-53. Berlin: De Gruyter Mouton. https://doi.org/10.1515/9783110261295-044

Louden, Mark L. 2020. “The English 'Infusion' in Pennsylvania German.” In English in the German-Speaking World, edited by Raymond Hickey, 384-407. Cambridge: Cambridge University Press. https://doi.org/10.1017/9781108768924.019

Nolt, Steven M., and Thomas J. Myers. 2007. Plain Diversity: Amish Cultures and Identities. Baltimore: Johns Hopkins University Press.

Stableford, Sue, and Wendy Mettger. 2007. "Plain Language: A Strategic Response to the Health Literacy Challenge.” Journal of Public Health Policy 28: 71-93. https://doi.org/10.1057/palgrave.jphp.3200102

Talpos, Sara. 2016. "Six Ways to Make a Hospital Better for Amish Patients.” Mosaic, May 18. https://mosaicscience.com/story/six-ways-make-hospital-better-amish-patients/.

Wenger, Anna Frances Z. 1995. "Cultural Context, Health and Health Care Decision Making." Journal of Transcultural Nursing 7 (1): 3-14. https://doi.org/10.1177/104365969500700102 